\title{
Apoio social relacionado ao uso de drogas entre universitários
}

\section{Social support related to drug use among university students}

\section{Vítor de Morais Alves Evangelista1 ${ }^{1}$ Aline Kadooka ${ }^{2}$ (1) Maria Laura Nogueira Pires ${ }^{3}$ Elizabeth Piemonte Constantino 4 (1)}

1'Autor para correspondência. Universidade Estadual Paulista Júlio de Mesquita Filho (Bauru). São Paulo, Brasil. vitordemorais@hotmail.com ${ }^{2-4}$ Universidade Estadual Paulista Júlio de Mesquita Filho (Assis). São Paulo, Brasil. alinekadooka@gmail.com, laurapires@assis.unesp.br, bethpie@assis.unesp.br

\begin{abstract}
RESUMO | O objetivo da presente pesquisa foi determinar a prevalência do uso de drogas psicoativas e investigar a sua associação com as redes de apoio social entre universitários. Os dados foram coletados por meio da aplicação de um questionário multidimensional em 227 universitários. Os resultados indicam que embora mais da metade já tenham consumido algum tipo de substância ilícita na vida, os índices de apoio social se mantiveram altos em todas as dimensões. Contudo, aqueles que estão expostos ao baixo apoio afetivo estão mais propensos ao uso moderado/alto de álcool e maconha, assim como aqueles que não possuem parentes com quem conversar possuem mais chances de usar álcool ou usar maconha. Outro dado importante consiste no fato de que estudantes que não possuem ou não praticam sua religião possuem mais chances de fazer uso de álcool.
\end{abstract}

PALAVRAS-CHAVE: Estudantes universitários. Drogas. Apoio Social.

\begin{abstract}
The aim of this research was to determine the prevalence of the use of psychoactive drugs and investigate its association with social support networks among university students. Data were collected through the application of a multidimensional questionnaire in 227 university students. The results indicate that while more than half have already consumed some kind of illegal substance in life, social support levels were high in all dimensions. However, those who are exposed to low emotional support are more likely to moderate / high use of alcohol and marijuana, as well as those who have no relatives to talk to possess more likely to use alcohol or use marijuana. Another important factor is the fact that students who do not have or do not practice their religion have more chances of alcohol use.
\end{abstract}

KEYWORDS: University students. Drugs. Social support. 


\section{Introdução}

A Lei n. 13.840/2019 alterou o Sistema Nacional de Políticas sobre Drogas (SISNAD), estabelecido em 2006, dando ênfase às comunidades terapêuticas, entretanto, ela sinaliza o fim de qualquer incentivo à Política de Redução de Danos (PRD). Enquanto a PRD investia em um modelo destinado à amenização de riscos de danos psicossociais, econômicos e biológicos, inserido nos espaços institucionais que formam a Rede de Atenção Psicossocial, ampliando estratégias de saúde preventivas ou redutoras das consequências do uso e abuso de drogas, respeitando a liberdade e reponsabilidade do usuário; a atual política tem como base o discurso de "guerra às drogas", partindo de uma lógica de proibicionismo que tem como intuito estimular as comunidades terapêuticas (CTs), instituições não governamentais, que podem ter algum vínculo religioso, e recebem usuários de drogas, com ênfases nas terapias de abstinência e isolamento. Para Brandão e Caracho (2019) uma das preocupações com a nova proposta está no fato de que as CTs, com grandes subsídios públicos e benefícios fiscais, se fundamentam em uma única forma de tratamento sem respaldo científico e sob a premissa de uma lógica religiosa. Os autores acreditam que o isolamento e abstinência, técnicas defendidas pelas CTs, mascaram a grande questão urbana brasileira: marginalização social e violação dos direitos humanos. Esse novo paradigma individualizante passa a transferir para o individual a resolução de um problema social.

Segundo o Relatório Mundial sobre Drogas, cerca de 275 milhões de pessoas em todo o mundo, equivalente a $5,6 \%$ da população mundial entre as idades de 15 e 64 anos, usaram drogas em pelo menos uma ocasião em 2016. Aproximadamente 31 milhões de pessoas que usam drogas sofrem algum tipo de distúrbio derivado desse consumo. Somente em 2015 faleceram 450.000 pessoas como resultado do consumo de drogas. Dessas mortes, 167.750 foram diretamente relacionadas aos transtornos por uso de drogas (principalmente overdose). Os restos das mortes podem ser atribuídos indiretamente ao uso de drogas, como aquelas relacionadas aos vírus HIV e à hepatite $C$ contraídos como resultado do uso inseguro de seringas (UNODOC, 2018).

São consideradas como drogas psicoativas ou psicotrópicas todas as substâncias que causam alteração no Sistema Nervoso Central (SNC) sejam elas legais ou ilegais classificadas em três grupos em função do tipo de efeito que causam ao SNC: depressoras, estimulantes e perturbadoras. Segundo a Organização Mundial de Saúde, essas substâncias ao entrarem em contato com o organismo, sob diversas vias de administração, produziriam alterações de comportamentos, humor e cognição, possuindo grande capacidade reforçadora. Ressalta-se que nem todas as substâncias psicoativas têm a capacidade de provocar dependência, pois muitas são utilizadas com a função de produzir efeitos benéficos, como o tratamento de doenças, sendo consideradas, assim, medicamentos (Brasil, 2017).

Ainda segundo o Relatório Mundial de Drogas (UNODOC, 2018), o uso de drogas e os danos associados a ele são mais elevados entre os jovens em comparação aos mais velhos. A maioria das pesquisas sugere que a adolescência precoce (12-14 anos), a tardia (15-17 anos) é um período de risco crítico para o início do uso de substâncias e pode atingir o pico entre os jovens (com idade entre 18 e 25 anos). É nessa faixa etária que os jovens da população geral apresentam as maiores frequências para o uso de substâncias psicoativas e para a incidência de comportamentos de risco (Elicker et al, 2015; Carlini, 2006), o que desperta a necessidade de estudos que sejam destinados à compreensão específica da realidade dos universitários, que concentram grande parte desses jovens.

Os universitários, dentre a população mais jovem, têm merecido destaque, ou pelos investimentos científicos que recebem ou pelas funções que exercerão na sociedade e consequentemente no desenvolvimento do país. Somado a isso, a determinação da "prevalência de uso e de opiniões sobre álcool e outras drogas, entre os universitários, é fonte potencial de informações sobre o comportamento e compreensão dessa referida população" (Brasil, 2017, p.17).

Adentrar a universidade instaura, muitas vezes, um período de grande autonomia e emancipação, possibilitando novas experiências, mas, para alguns, este momento pode se constituir em um período de grande vulnerabilidade, o que tornaria os universitários mais suscetíveis ao uso de drogas e suas consequências. Os anos na universidade são períodos de transição única, em que o aluno tenta estabelecer uma identidade e construir uma nova rede social (Graner, \& Cerqueira, 2019). O uso de substâncias psicoativas é muitas vezes parte deste processo, 
e na faculdade muitos alunos desenvolvem um padrão de consumo que os colocam em risco durante os anos como universitários e possivelmente gerará consequências adversas durante a idade adulta. Nesse sentido, percebe-se que o uso de drogas tem sido associado a vários problemas entre os universitários, uma vez que os predispõem a: a) acidentes automobilísticos (especialmente por beber e dirigir e pegar carona com motorista alcoolizado), b) episódios de violência interpessoal, c) comportamento sexual de risco (especialmente pelo aumento do número de parceiros sexuais e uso inconsistente de preservativos quando sob o efeito de álcool e outras substâncias psicoativas), além de causar, d) prejuízos acadêmicos, e) distúrbios do sono, e f) mudanças do hábito alimentar, g) prejuízo do desempenho atlético (Brasil, 2010; Targino \& Hayasida, 2018). O uso de drogas por estudantes universitários é foco de vários estudos, primeiro pela maior preocupação com o uso prejudicial e abusivo, e, segundo, como intervenções preventivas eficazes para a redução desse consumo (Brasil, 2010).

Embora exista um aumento quantitativo de estabelecimentos de ensino superior no Brasil, principalmente na última década, o conhecimento sobre a relação do ambiente acadêmico com a qualidade de vida da população universitária ainda é escasso. Existe uma carência de estudos que identifiquem o perfil do estudante universitário, sobretudo em relação aos processos de ingresso, inserção na vida universitária e os aspectos que podem intervir na sua permanência (Siqueira et al. 2017).

Identificar esses fatores é de suma importância, pois só assim será possível a elaboração de políticas preventivas eficazes relacionadas ao consumo de substâncias psicoativas entre os universitários brasileiros. Estudos sobre uso de sustâncias psicoativas em determinadas populações definem e ajudam a elaborar tipos de intervenções a serem realizadas, e para que isso ocorra é de grande necessidade o conhecimento específico sobre o uso de determinadas substâncias em certos ambientes e uma análise sobre a existência e funcionamento de programas de prevenção (Carlini, 2006; Galduroz et al., 2005).

Lima (2013) ressalta a necessidade de uma política pública que forneça mudanças estruturais sinalizando reais oportunidades de uma vida mais digna aos jovens além de contemplar mudanças nos contextos de socialização e educação. O próprio ambiente acadêmico pode se tornar palco da discussão e reflexão para a elaboração de estratégias na educação preventiva ao uso e abuso de drogas. Para a autora, a grande contribuição das universidades está na aproximação entre teoria e prática e na possibilidade de criação de intervenções mais efetivas. Para Campagnac e Santos (2018) existe uma grande debilidade quanto ao avanço no debate sobre a temática das drogas e na forma com que esta questão é lidada nas esferas criminal e da segurança pública. O Estado atua tendo como referencial a política de enfrentamento e encarceramento, fortalecendo a "lógica de guerra" e o "combate ao inimigo", assim como a seleção punitiva, ou seja, o sistema penal seleciona e criminaliza ações e pessoas com base em sua classe e posição social. Ao longo dos anos, o viés punitivo e repressivo das políticas públicas contribuiu significativamente para o aumento da letalidade, do encarceramento e da diversificação dos delitos, sendo que os efeitos dessa política, embora percebidos na sociedade, são mais sentidos pelas populações em vulnerabilidade social.

Souza (2010) destaca o apoio social como um recurso efetivo de enfrentamento no problema de uso de substâncias psicoativas devido ao efeito protetor sobre as relações interpessoais. $\mathrm{O}$ apoio social pode ser entendido como um dos alicerces que sustentam a superação de adversidades sendo um conceito que direciona certas funções de um grupo para com o indivíduo, que podem ser familiares, escolares, de amigos, dentre outros, sendo esse conjunto denominado de redes de relações ou apoio social. As redes de apoio social podem ser entendidas como a soma das relações que é vista como significativa por determinado indivíduo, tendo essas redes como função contribuir para o próprio reconhecimento do indivíduo e construção da autoimagem (Squassoni, Matsukura, \& Panúnico-Pinto, 2016). Sherbourne e Stewart (1991) sugerem uma diferenciação entre os conceitos de rede social e apoio social onde enquanto o primeiro se caracteriza como um grupo de pessoas com o qual o indivíduo mantém contato ou vínculo social, o segundo conceito se refere ao tipo de recurso apresentado por outras pessoas em situações de necessidade, podendo ser mensurável de acordo com a percepção e o grau das relações interpessoais. A rede de apoio social pode ser classificada como um conjunto de pessoas significativas que estruturam os relacionamentos percebidos e recebidos. 
Essas redes sociais viriam a constituir uma maneira de intervenção que proporcionariam mudanças concretas na vida do indivíduo e na sociedade ou organização na qual este esteja inserido estando, portanto, o apoio social intrinsecamente relacionado à capacidade de enfrentamento, aos processos de resiliência e ao desenvolvimento adaptativo sendo que as relações estabelecidas pelos indivíduos com outras pessoas, provenientes de diferentes microssistemas, como amigos, famílias, e escolas, dentre outros, podem vir a proporcionar o apoio social. Para Chor, Griep, Lopes e Faerstein (2001) o apoio social refere-se a um sistema de relações onde os indivíduos recebem ajuda do tipo material, emocional ou de informação para enfrentarem situações estressantes. Seria um processo de reciprocidade que geraria efeitos positivos tanto para o sujeito que recebe como também àquele que oferece o apoio.

Constituindo a interface entre o meio social e o sujeito, o apoio social é considerado uma importantíssima dimensão do desenvolvimento. O apoio social relaciona-se à percepção do sujeito frente ao seu mundo social, a maneira que este interage, as respectivas estratégias e competências para criar vínculos e estabelece-los, quais recursos the são oferecidos como proteção e força em situações de risco além de reforçar a autoimagem e contribuir para o aumento da competência individual, a rede de apoio social está comprometida à saúde e ao bem-estar dos indivíduos, funcionando muitas vezes como facilitadora do processo de adaptação a distúrbios físicos e emocionais e situações de estresse. Alves e Dell' Aglio (2015) ao investigar a relação entre apoio social e comportamentos de risco (comportamentos sexual, infracional, suicida e uso de substâncias) em 374 adolescentes de Porto Alegre, entre 12 e 18 anos, de escolas públicas, identificaram maior envolvimento em comportamentos de risco em adolescentes mais velhos: meninos envolveram-se mais em comportamento infracional e sexual de risco enquanto as meninas em comportamentos suicidas. Já o apoio da família e dos professores se mostrou um fator protetor com relação ao envolvimento em comportamentos de risco.

Barceló, Socias e Brage (2015) apontam que as fontes de apoio social impactam de diferentes formas com relação à faixa etária, à fase de desenvolvimento e as necessidades vigentes de cada pessoa. No estudo realizado com alunos espanhóis da Universitat de les Illes Balears, os autores relatam que os resultados apontaram que os alunos possuiam um bom nível de apoio social (informativo, emocional e material) e uma boa rede social, tanto qualitativa quanto quantitativa. Entretanto, foram encontradas diferenças expressivas entre as redes sociais e de apoio social nas análises por sexo, faixa etária e nível educacional. Outro dado significativo é que os alunos que participam da vida acadêmica apresentam mudanças positivas em suas redes e no apoio social, sendo que as maiores mudanças ocorrem nos primeiros anos na universidade.

A rede social possui caráter dinâmico, modificando-se de acordo com o tempo e a vida das pessoas envolvidas. As oportunidades oferecidas pela rede de relações de um indivíduo, que viriam a lhe proporcionar sustentação (emocional, de informação, material, afetiva, etc.) frente a algumas situações de estresse, ou crise adaptativa, são chamadas de apoio social (Sherbourne \& Stewart, 1991). Dessa forma, o apoio social pode ser compreendido como a existência ou disponibilidade de pessoas que demonstram preocupação, confiança e nos valorizam. As redes sociais viriam a constituir uma maneira de intervenção que proporcionaria mudanças concretas na vida do indivíduo e na sociedade ou organização na qual este esteja inserido. Vale lembrar que existe uma grande diversidade de representações para o uso de drogas por parte de jovens, tais como sociabilidade, interação social, prazer, estilos de vida e automedicação, sendo que estes se mostraram relacionados com os diferentes contextos vivenciados, os efeitos das substâncias e as motivações dos jovens estudados. A diversidade de representações para o uso de drogas referente aos diferentes contextos de uso e aos usuários e sua relação com as drogas não compõe um grupo homogêneo de sujeitos cuja experiência se dá de maneira uniforme (Lima, 2013).

O presente estudo tem como objetivo geral determinar a prevalência do uso de drogas psicoativas entre estudantes universitários e investigar a sua associação com as redes de apoio social. A presente pesquisa justifica-se pela necessidade de estudos regionais envolvendo prevalência, opiniões e padrão do uso de álcool, tabaco e outras drogas e por fornecer dados objetivos e auxiliares para a análise e dimensionamento das redes de apoio e do apoio social, provendo informações indispensáveis para o desenvolvimento de estratégias e elaboração de programas preventivos junto à população. 


\section{Método}

Trata-se de estudo de desenho transversal, quantitativo, exploratório e descritivo. A pesquisa utilizou dados coletados por meio da aplicação de um questionário multidimensional, fechado, de autopreenchimento e sem identificação pessoal, aplicados coletivamente em sala de aula, sem a presença do professor e respondidos voluntariamente.

A população do estudo foi constituída de estudantes matriculados nos cursos de graduação presencial. Com base no número de matriculados ( $\mathrm{N}=1.645)$, estimou-se inicialmente o tamanho mínimo da amostra em 312 estudantes, com margem de erro de 5\%, intervalo de confiança de $95 \%$ e proporção esperada de $50 \%$. Excluídos os questionários invalidados e os deixados em branco, 227 questionários foram válidos para análise, sendo 33,6\% provenientes de alunos da área de conhecimento Ciências Biológicas e 66,4\% da área de Humanas.

O questionário possui questões referentes aos dados sociodemográficos e socioeconômicos, e caracterização do curso universitário, estruturado e fundamentado conforme o questionário utilizado no I Levantamento Nacional sobre o uso de álcool, tabaco e outras drogas entre universitários das 27 Capitais, realizado pela Secretaria Nacional de Políticas sobre Drogas (SENAD) em 2010.

Outros três instrumentos foram utilizados: Alcohol, Smoking and Substance Involving Screening Test ASSIST: Teste de triagem do envolvimento com álcool, cigarro e outras substâncias (Henrique, De Micheli, Lacerda, Lacerda \& Formigoni, 2004), a Escala de Apoio Social: escala desenvolvida por Sherbourne e Stewart (1991), validada para o Brasil por Griep, Chor, Faerstein, Werneck e Lopes (2005) e a Medida de Rede Social do Estudo Pró-Saúde adaptada e validada por Chor, Griep, Lopes e Faerstein (2001).

Os dados foram analisados por meio de medidas descritivas (frequências, em número de indivíduos e em porcentagem, média e desvio-padrão) e comparações entre médias foram feitas por meio do Teste $t$ de Student para amostras independentes, com o uso do programa Statistica 6.1 (StatSoft, Inc.). As medidas de associação foram feitas por meio do Teste Z, e a razão de prevalência (RP) foi utilizada para avaliar a associação entre fatores de exposição e consumo de álcool e drogas na população estudada.
Esta pesquisa foi aprovada pelo comitê de ética (CAAE 01312312.7.0000.5401) e todos os participantes assinaram termo de consentimento e esclarecido antes de qualquer procedimento do estudo fosse iniciado.

\section{Resultados e discussão}

Os dados analisados indicaram que dentre os universitários respondentes, 34,8\% são do sexo masculino e $63,0 \%$ do sexo feminino, enquanto a idade média dos alunos respondentes corresponde a 21 anos. Dentre os alunos pesquisados, 38,3 \% relatam morar em Repúblicas Estudantis, 33,3\% com Pais, padrastos ou outros familiares, 23,3\% com Amigos, 12,8\% moram Sozinhos e 5,7\% residem na Moradia da Instituição de Ensino. Acerca do exercício de atividade remunerada nos últimos 6 meses, mais que a metade $(67,4 \%)$ dos estudantes relataram não exercer atividade remunerada, enquanto $23,8 \%$ exerceu atividades até $20 \mathrm{~h}$ semanais e outros $8,4 \%$ até $40 \mathrm{~h}$ semanais. Com relação à religião, 39,6\% dos alunos respondentes relataram não possuir religião. A mesma porcentagem, $39.6 \%$, corresponde aos alunos católicos. 3,9\% dos alunos pesquisados possuem religião evangélica ou protestante, enquanto $4,8 \%$ relataram ser espíritas e outros mesmos 4,8 relatam possuir outro tipo de religião. A respeito da prática da religião, pouco mais que a metade, 53\% disseram não praticar a religião, enquanto $21,6 \%$ relataram praticar apenas em eventos especiais e a mesma porcentagem, $21,6 \%$, relataram praticar a religião mais de uma vez por mês. A maior parte dos universitários respondentes $(78,9 \%)$ declarou estar cursando, pela primeira vez um ensino de graduação. Por outro lado, $15,4 \%$ dos estudantes investigados já iniciaram, mas não concluíram o outro curso. Outros 4,4\%, já possuíam graduação. Com relação à satisfação da escolha do curso, 92,5\% $(n=210)$ dos universitários estão satisfeitos, enquanto $7,0 \%(n=16)$ se mostraram insatisfeitos.

De acordo com a pontuação do Alcohol, Smoking and Substance Involvement Screening Test (ASSIST), o consumo de álcool foi classificado como sendo de baixo risco (0-10 pontos); risco moderado, (11-26 pontos); e alto risco (27 ou mais pontos). A análise do ASSIST (Tabela 1) nos mostra que $71,4 \%$ dos alunos apresentaram consumo de álcool com baixo risco, $25,6 \%$ fazem uso de risco moderado e $2,1 \%$ foram considerados como usuários de alto risco. Com relação ao uso do tabaco, $78,4 \%$ apresentam consumo 
de baixo risco e $21,6 \%$ de alto risco. Dentre o consumo de outras substâncias, destaca-se o uso de Maconha/ Haxixe/Skank com $82,4 \%$ como consumo de baixo risco e $17,6 \%$ com risco moderado e o uso de cocaína com $96,5 \%$ considerado como de baixo risco e 3,5\% de risco moderado.

Tabela 1. Prevalência de universitários que realizam uso de risco

\begin{tabular}{|c|c|c|c|c|c|c|}
\hline \multirow{3}{*}{ Substância Psicotrópica } & \multicolumn{6}{|c|}{ ASSIST } \\
\hline & \multicolumn{3}{|c|}{ Baixo Risco \% (n) } & \multicolumn{3}{|c|}{ Moderado/Alto Risco \% (n) } \\
\hline & Total & Masculino & Feminino & Total & Masculino & Feminino \\
\hline Álcool & $\begin{array}{l}71,4 \\
(162)\end{array}$ & $30,2(48 / 159)$ & $\begin{array}{c}69,8 \\
(111 / 159)\end{array}$ & $\begin{array}{l}27,8 \\
(63)\end{array}$ & $47,5(29 / 61)$ & $\begin{array}{c}52,5 \\
(32 / 61)\end{array}$ \\
\hline Tabaco e Derivados & $\begin{array}{l}78,4 \\
(178)\end{array}$ & $33,1(57 / 172)$ & $\begin{array}{c}66,9 \\
(115 / 172)\end{array}$ & $\begin{array}{l}21,6 \\
(49)\end{array}$ & $41,7(20 / 48)$ & $\begin{array}{c}58,3 \\
(28 / 48)\end{array}$ \\
\hline Maconha/Haxixe/Skank & $\begin{array}{c}82,4 \\
(187)\end{array}$ & $\begin{array}{c}33 \\
(60 / 182)\end{array}$ & $\begin{array}{c}67 \\
(122 / 182)\end{array}$ & $\begin{array}{l}17,6 \\
(40)\end{array}$ & $44,8(17 / 38)$ & $\begin{array}{c}55,2 \\
(21 / 38)\end{array}$ \\
\hline Cocaína & $\begin{array}{c}96,5 \\
(219)\end{array}$ & $33,5(71 / 212)$ & $\begin{array}{c}66,5 \\
(141 / 212)\end{array}$ & $\begin{array}{l}3,5 \\
(8)\end{array}$ & $\begin{array}{l}75,0 \\
(6 / 8)\end{array}$ & $\begin{array}{l}25,0 \\
(2 / 8)\end{array}$ \\
\hline Merla & $\begin{array}{l}99,6 \\
(226)\end{array}$ & $34,7(76 / 219)$ & $\begin{array}{c}65,3 \\
(143 / 219)\end{array}$ & $\begin{array}{l}0,4 \\
(1)\end{array}$ & $\begin{array}{c}100 \\
(1 / 1)\end{array}$ & 0 \\
\hline Crack & $\begin{array}{l}99,1 \\
(225)\end{array}$ & $34,9(76 / 218)$ & $\begin{array}{c}65,1 \\
(142 / 218)\end{array}$ & $\begin{array}{l}0,9 \\
(2)\end{array}$ & $\begin{array}{c}50 \\
(1 / 2)\end{array}$ & $\begin{array}{c}50 \\
(1 / 2)\end{array}$ \\
\hline Alucinógenos & $\begin{array}{l}97,4 \\
(221)\end{array}$ & $34,0(73 / 215)$ & $\begin{array}{c}66,0 \\
(142 / 215)\end{array}$ & $\begin{array}{r}2,6 \\
(6)\end{array}$ & $\begin{array}{l}80,0 \\
(4 / 5)\end{array}$ & $\begin{array}{l}20,0 \\
(1 / 5)\end{array}$ \\
\hline Cetamina $®$ & $\begin{array}{l}99,6 \\
(226)\end{array}$ & $34,0(73 / 215)$ & $\begin{array}{c}66,0 \\
(142 / 215)\end{array}$ & $\begin{array}{l}0,4 \\
(1)\end{array}$ & $\begin{array}{c}100 \\
(1 / 1)\end{array}$ & 0 \\
\hline Chá de Ayahuasca & $\begin{array}{c}99,1 \\
(225) \\
\end{array}$ & $34,9(76 / 218)$ & $\begin{array}{c}65,1 \\
(142 / 218) \\
\end{array}$ & $\begin{array}{l}0,9 \\
(2)\end{array}$ & $\begin{array}{c}50 \\
(1 / 2) \\
\end{array}$ & $\begin{array}{c}50 \\
(1 / 2) \\
\end{array}$ \\
\hline Ecstasy & $\begin{array}{l}99,1 \\
(225)\end{array}$ & $34,9(76 / 218)$ & $\begin{array}{c}65,1 \\
(142 / 218)\end{array}$ & $\begin{array}{l}0,9 \\
(2)\end{array}$ & $\begin{array}{c}50 \\
(1 / 2)\end{array}$ & $\begin{array}{c}50 \\
(1 / 2)\end{array}$ \\
\hline Esteroides/ Anabolizantes & $\begin{array}{c}99,6 \\
(226)\end{array}$ & $34,7(76 / 219)$ & $\begin{array}{c}65,3 \\
(143 / 219)\end{array}$ & $\begin{array}{l}0,4 \\
(1)\end{array}$ & $\begin{array}{c}100 \\
(1 / 1)\end{array}$ & 0 \\
\hline Tranquilizantes/Ansiolíticos & $\begin{array}{l}96,5 \\
(219)\end{array}$ & $35,9(76 / 212)$ & $\begin{array}{c}64,1 \\
(136 / 212)\end{array}$ & $\begin{array}{l}3,5 \\
(8)\end{array}$ & $\begin{array}{l}12,5 \\
(1 / 8)\end{array}$ & $\begin{array}{l}87,5 \\
(7 / 8)\end{array}$ \\
\hline Sedativos ou Barbitúricos & $\begin{array}{l}98,7 \\
(224)\end{array}$ & $35,0(76 / 217)$ & $\begin{array}{c}65,0 \\
(141 / 217)\end{array}$ & $\begin{array}{l}1,3 \\
(3)\end{array}$ & $\begin{array}{l}33,3 \\
(1 / 3)\end{array}$ & $\begin{array}{l}66,7 \\
(2 / 3)\end{array}$ \\
\hline Analgésicos Opiáceos & $\begin{array}{l}99,1 \\
(225)\end{array}$ & $34,9(76 / 218)$ & $\begin{array}{c}65,1 \\
(142 / 218)\end{array}$ & $\begin{array}{l}0,9 \\
(2)\end{array}$ & $\begin{array}{c}50 \\
(1 / 2)\end{array}$ & $\begin{array}{c}50 \\
(1 / 2)\end{array}$ \\
\hline Xaropes à Base de Codeína & $\begin{array}{l}99,1 \\
(225)\end{array}$ & $34,9(76 / 218)$ & $\begin{array}{c}65,1 \\
(142 / 218)\end{array}$ & $\begin{array}{l}0,9 \\
(2)\end{array}$ & $\begin{array}{c}50 \\
(1 / 2)\end{array}$ & $\begin{array}{c}50 \\
(1 / 2)\end{array}$ \\
\hline Anticolinérgicos & $\begin{array}{l}99,6 \\
(226)\end{array}$ & $34,7(76 / 219)$ & $\begin{array}{c}65,3 \\
(143 / 219)\end{array}$ & $\begin{array}{l}0,4 \\
(1)\end{array}$ & $\begin{array}{c}100 \\
(1 / 1)\end{array}$ & 0 \\
\hline Heroína & $\begin{array}{c}99,6 \\
(226)\end{array}$ & $34,7(76 / 219)$ & $\begin{array}{c}65,3 \\
(143 / 219) \\
\end{array}$ & $\begin{array}{l}0,4 \\
(1) \\
\end{array}$ & $\begin{array}{c}100 \\
(1 / 1)\end{array}$ & 0 \\
\hline Anfetaminas & $\begin{array}{l}99,1 \\
(225)\end{array}$ & $34,4(75 / 218)$ & $\begin{array}{c}65,6 \\
(143 / 218)\end{array}$ & $\begin{array}{l}0,9 \\
(2)\end{array}$ & $\begin{array}{c}100 \\
(2 / 2)\end{array}$ & 0 \\
\hline Drogas Sintéticas & $\begin{array}{c}98,2 \\
(223)\end{array}$ & $34,3(74 / 216)$ & $\begin{array}{c}65,7 \\
(142 / 216)\end{array}$ & $\begin{array}{l}1,8 \\
(4)\end{array}$ & $\begin{array}{l}75,0 \\
(3 / 4)\end{array}$ & $\begin{array}{l}25,0 \\
(1 / 4)\end{array}$ \\
\hline
\end{tabular}


Ainda com relação à Tabela 1, entre os universitários do sexo masculino, as drogas mais frequentemente associadas a uso de risco moderado/alto, foram: álcool (47,5\%); tabaco e derivados $(41,7 \%)$ e maconha/ haxixe/ Skank $(44,8)$. Entre as mulheres, as substâncias mais associadas ao uso de risco moderado/alto) foram: tabaco e derivados (58,3\%), maconha/haxixe/ skank (55,2\%) e álcool (52,5\%).

Como podemos observar na Tabela 2, a medida de rede compreende um bloco de perguntas para avaliar a rede social, investigando, entre outros aspectos, o número de parentes e amigos íntimos (aqueles com quem você se sente à vontade e pode falar sobre quase tudo), a situação conjugal (se mora sozinho ou não) e a participação em atividades estudantis, sindicatos, partidos, associações e trabalho voluntário. Com relação ao número de parentes com que se sentem à vontade para falar sobre quase tudo o escore médio foi de 2,3 parentes, já com relação ao número de amigos, foi de 4,8 amigos. Dentre os alunos pesquisados, $17,2 \%$ não possuem nenhum parente com o qual se sente a vontade para poder falar de quase tudo, enquanto $82,4 \%$ possuem pelo menos um. Com relação ao número de amigos com o qual se sentem a vontade para poder falar de quase tudo, 91,2\% possuem pelo menos um e 6,2\% não possuem nenhum amigo. Sobre as participações, nos últimos 12 meses, em atividades esportivas ou atividades artísticas em grupo, 52\% relataram não participar de nenhuma atividade, 15\% participam mais de uma vez por semana e $11,9 \%$ participam de duas a três vezes por semana. Ainda nos últimos 12 meses, 74\% dos estudantes não participam de reuniões estudantis ou de associações enquanto $13,2 \%$ participaram apenas alguma vez ao ano. Com relação à participação em trabalhos voluntários nos últimos 12 meses, 76,2\% dos universitários nunca participaram e $8,8 \%$ só participaram uma vez no ano.

Tabela 2. Análise de Medidas de Rede

\begin{tabular}{|c|c|c|}
\hline \multirow{2}{*}{ Medidas de Rede } & \multicolumn{2}{|c|}{ Alunos Pesquisados } \\
\hline & $N$ & $\%$ \\
\hline \multicolumn{3}{|c|}{ Número de parentes com que você se sente à vontade } \\
\hline Pelo menos um & 187 & 82,4 \\
\hline Nenhum & 39 & 17,2 \\
\hline Não responderam & 1 & 0,4 \\
\hline \multicolumn{3}{|c|}{ Número de amigos com que você se sente à vontade } \\
\hline Pelo menos um & 207 & 91,2 \\
\hline Nenhum & 14 & 6,2 \\
\hline Não responderam & 6 & 2,6 \\
\hline \multicolumn{3}{|l|}{ Frequência atividades esportivas, últimos 12 meses. } \\
\hline Não participei & 118 & 52,0 \\
\hline Mais de uma vez por semana & 34 & 15,0 \\
\hline \multicolumn{3}{|l|}{ Frequência atividades esportivas, últimos 12 meses. } \\
\hline Duas a três vezes por semana & 27 & 11,9 \\
\hline Algumas vezes no ano & 23 & 10,1 \\
\hline Uma vez por semana & 20 & 8,8 \\
\hline Uma vez no ano & 5 & 2,2 \\
\hline \multicolumn{3}{|l|}{ Frequência reuniões, últimos 12 meses. } \\
\hline Não participei & 168 & 74,0 \\
\hline Algumas vezes no ano & 30 & 13,2 \\
\hline Uma vez por semana & 12 & 5,3 \\
\hline Uma vez no ano & 8 & 3,5 \\
\hline Mais de uma vez por semana & 7 & 3,1 \\
\hline Duas a três vezes por semana & 2 & 0,9 \\
\hline \multicolumn{3}{|l|}{ Frequência trabalho voluntário, últimos 12 meses. } \\
\hline Não participei & 173 & 76,2 \\
\hline Algumas vezes no ano & 20 & 8,8 \\
\hline Uma vez por semana & 15 & 6,6 \\
\hline Mais de uma vez por semana & 13 & 5,7 \\
\hline Duas a três vezes por semana & 2 & 0,9 \\
\hline Uma vez no ano & 4 & 1,8 \\
\hline
\end{tabular}


Na Tabela 3, pode-se observar que as análises da Escala de Apoio Social indicam maiores escores médios na Interação Social Positiva $(82,5)$ e no Apoio Afetivo $(83,1)$, seguidos pelo Apoio de Informação $(76,5)$, Apoio Emocional $(76,1)$ e Apoio Material $(70,2)$.

Tabela 3. Análise das dimensões do apoio social

\begin{tabular}{cc}
\hline Dimensões & Escore Médio (dp) \\
\hline Apoio Material & $70,2(22,0)$ \\
\hline Apoio Emocional & $76,1(19,7)$ \\
\hline Apoio de Informação & $76,5(20,8)$ \\
\hline Apoio Afetivo & $83,1(18,4)$ \\
\hline Interação Social Positiva & $82,5(16,6)$ \\
\hline
\end{tabular}

Os cálculos da razão de prevalência (RP) para o uso de drogas ilícitas na vida, no ano, nos últimos três meses e no mês relacionado ao baixo apoio material, apoio emocional, apoio informativo, apoio social e interação social positiva baixa apontaram resultados estatisticamente não significativos (Tabela 4).

Tabela 4. Razão de prevalência entre apoio social e uso de drogas

\begin{tabular}{|c|c|c|c|c|}
\hline Variável de exposição & $\begin{array}{l}\text { Uso de droga } \\
\text { ilícita na vida } \\
\text { RP (IC95\%) }\end{array}$ & $\begin{array}{l}\text { Uso de droga ilícita } \\
\text { no ano } \\
\text { RP (IC95\%) }\end{array}$ & $\begin{array}{c}\text { Uso de droga ilícita } \\
\text { nos últimos três } \\
\text { meses } \\
\text { RP (IC95\%) }\end{array}$ & $\begin{array}{l}\text { Uso de droga } \\
\text { ilícita no mês } \\
\text { RP (IC95\%) }\end{array}$ \\
\hline Apoio Material Baixo & $1,0(0,7-1,3)$ & $1,0(0,6-1,5)$ & $1,0(0,7-1,6)$ & $1,1(0,7-1,7)$ \\
\hline Apoio Emocional Baixo & $1,0(0,8-1,4)$ & $0,9(0,6-1,3)$ & $1,0(0,7-1,6)$ & $0,9(0,5-1,5)$ \\
\hline Apoio Informativo Baixo & $1,1(0,8-1,4)$ & $0,9(0,6-1,4)$ & $1,0(0,7-1,6)$ & $1,0(0,6-1,6)$ \\
\hline Interação Social Positiva Baixa & $0,7(0,4-1,1)$ & $0,6(0,3-1,2)$ & $0,5(0,2-1,1)$ & $0,5(0,2-1,1)$ \\
\hline Apoio Social Baixo (Soma Total) & $1,0(0,7-1,3)$ & $0,8(0,5-1,3)$ & $0,9(0,6-1,5)$ & $1,0(0,6-1,6)$ \\
\hline
\end{tabular}

Já na Tabela 5, os cálculos da razão de prevalência para o uso moderado/alto de álcool e uso moderado/alto de maconha pelas baixas dimensões do apoio social apontaram resultado estatisticamente significativo: os universitários que foram expostos ao baixo Apoio Afetivo apresentaram mais chances de uso moderado/alto de álcool e também moderado/alto de maconha.

Tabela 5. Razão de prevalência entre apoio social e ASSIST

\begin{tabular}{lcc}
\hline \multicolumn{1}{c}{ Variável de exposição } & $\begin{array}{c}\text { ASSIST Álcool } \\
\text { moderado/alto } \\
\text { RP (IC95\%) }\end{array}$ & $\begin{array}{c}\text { ASSIST Maconha moderado/alto } \\
\text { RP }(I C 95 \%)\end{array}$ \\
\hline Apoio Material Baixo & $0,7(0,5-1,2)$ & $0,7(0,4-1,4)$ \\
\hline Apoio Emocional Baixo & $1,2(0,7-1,8)$ & $1,0(0,5-1,9)$ \\
\hline Apoio Informativo Baixo & $1,0(0,6-1,6)$ & $0,9(0,5-1,7)$ \\
\hline Apoio Afetivo Baixo & $1,5(1,0-2,3)$ & $1,3(0,7-2,3)$ \\
\hline Interação Social Positiva Baixo & $0,8(0,5-1,4)$ & $0,5(0,2-1,2)$ \\
\hline Apoio Social Baixo (Soma Total) & $1,1(0,7-1,8)$ & $0,6(0,3-1,3)$ \\
\hline
\end{tabular}


Na tabela 6, cálculos de Razão de Prevalência, envolvendo uso de álcool e uso de maconha relacionados às diferentes variáveis de exposição, indicaram que estudantes que não possuem religião tiveram mais chances de uso de álcool no último mês. Já sobre o uso de maconha, aqueles que não possuem religião têm duas vezes mais chances de terem consumido na vida, e aproximadamente quatro vezes mais chances no último mês. Já aqueles que não praticam a religião tiveram mais chance de uso de álcool no último mês. Essa mesma variável parece influir no uso de maconha na vida (RP 1,7) e significativamente no último mês (RP 3,0). Com relação ao sexo, indivíduos do sexo masculino apresentam mais chances de uso de maconha na vida e no último mês respectivamente. Dentre as variáveis pertencentes às medidas de rede, a relacionada a não execução de trabalho voluntário apresentou dado estatisticamente significativo com relação ao uso de álcool no último mês (RP 1.2). Aqueles que não possuem parentes para conversar também possuem mais chances de uso de álcool no último mês, além de usar maconha durante a vida.

Tabela 6. Razão de prevalência entre variáveis de exposição

\begin{tabular}{lcccc}
\hline \multirow{2}{*}{ Variável de exposição } & \multicolumn{2}{c}{$\begin{array}{c}\text { Uso de álcool } \\
\text { RP (IC95\%) }\end{array}$} & \multicolumn{2}{c}{$\begin{array}{c}\text { Uso de maconha } \\
\text { RP (IC95\%) }\end{array}$} \\
\cline { 2 - 5 } & Na vida & Último mês & Na vida & Último mês \\
\hline \multirow{2}{*}{ Não ter religião } & 1,0 & 1,3 & 2,2 & 3,9 \\
& $(1,0-1,1)$ & $(1,1-1,5)$ & $(1,7-2,9)$ & $(2,2-6,7)$ \\
\hline \multirow{2}{*}{ Não praticar religião } & 1,1 & 1,3 & 1,7 & 3,0 \\
& $(1,0-1,1)$ & $(1,0-1,5)$ & $(1,2-2,4)$ & $(1,6-5,9)$ \\
\hline \multirow{2}{*}{ Sexo masculino } & 1,0 & 1,1 & 1,3 & 1,7 \\
& $(0,9-1,0)$ & $(1,0-1,4)$ & $(1,0-1,7)$ & $(1,0-2,9)$ \\
\hline \multirow{2}{*}{ Não ter parentes conversar } & 1,0 & 1,3 & 1,6 & 2,3 \\
& $(0,9-1,1)$ & $(1,1-1,5)$ & $(1,2-2,1)$ & $(1,4-3,7)$ \\
\hline Não participar atividades esportivas ou & 1,0 & 0,8 & 0,8 & 0,8 \\
artísticas em grupo & $(1,0-1,1)$ & $(0,7-1,0)$ & $(0,6-1,1)$ & $(0,5-1,3)$ \\
\hline \multirow{2}{*}{ Não participar de reuniões } & 1,0 & 0,8 & 0,7 & 0,6 \\
& $(0,9-1,0)$ & $(0,7-1,0)$ & $(0,6-1,0)$ & $(0,4-0,9)$ \\
\hline Não fazer trabalho voluntário & 1,0 & 1,2 & 1,1 & 0,9 \\
& $(0,9-1,1)$ & $(1,0-1,5)$ & $(0,8-1,5)$ & $(0,5-1,5)$ \\
\hline
\end{tabular}

O período universitário é visto como uma fase de maior autonomia e de busca por novas experiências, o que de certa forma expõe o jovem a vulnerabilidades, sendo o uso de drogas uma dessas. Um grande agravante do consumo de substâncias psicoativas é quando ele se torna uma forma de obter um papel no grupo, de conquistar apoio e cumplicidade dos pares, descontração e passa a se associado à maturidade (Eckschmidt, Andrade \& Oliveira, 2013). Em um estudo envolvendo jovens participantes de programas de cumprimento de medidas alternativas em Belo Horizonte, Lima (2013) verificou que as relações estabelecidas entre masculinidade e juventude podem ocasionar maiores níveis de vulnerabilidade frente a diversos agravos e, particularmente, ao uso e abuso de drogas. Para a autora, o ato de "enfrentar riscos" é um elemento valorizado na construção de um ideal de virilidade, o que acarreta, muitas vezes, na amenização das vulnerabilidades em prol da aquisição das "insígnias da masculinidade".

Em outro estudo, o maior uso de álcool e tabaco por essa população específica também está relacionado a fatores já identificados tais como "não possuir religião" ou "não participar de celebrações religiosas" (Sanchez \& Nappo, 2007). Com relação ao apoio social, as análises indicaram altos níveis de Apoio Social. Entretanto, os universitários expostos a baixo Apoio Afetivo apresentaram mais probabilidade de uso moderado/alto de álcool e moderado/ alto de maconha. Com relação aos níveis baixos de apoio social, o apoio afetivo teve maior significância quando comparado ao nível de envolvimento com álcool, sendo 25,5\% para uso de baixo risco e 38,1\% para uso moderado/alto. Dentre as variáveis pertencentes às medidas de rede, a "não execução de trabalho voluntário" está relacionado ao uso de álcool no último mês e os universitários que "não possuem parentes para conversar" apresentaram maior probabilidade de usar álcool e maconha. 
Griep et al. (2005) afirma que embora a rede seja definida como grupo de pessoas nas quais o indivíduo possa ter contato ou vínculo social, essa rede pode ou não fornecer apoio em situações no decorre da vida. Lima, Gomide e Farinha (2015) ressaltam que o ambiente universitário tende a propiciar o uso de drogas, especialmente de bebidas alcoólicas, tendo em vista a disponibilidade dessa substância ao redor dos campis das universidades, nas festas que promovem o uso de álcool, de variáveis culturais e sociais. Segundo os autores existe uma romantização com relação ao início da vida acadêmica e o uso de drogas, assim como a experimentação de novos estados de consciência e novas vivências. Um dos principais motivos que os levam a usar drogas pela primeira vez é justamente para participar do grupo de amigos. Dentre os universitários, ter amigos que não desaprovam o uso de substâncias psicoativas está dentre os vários fatores de risco para uso de álcool e outras drogas.

Segundo Matias e Martinelli (2017) a rede social que os estudantes constituem é um fator de grande relevância para a adaptação ao ensino superior, pois a vida acadêmica implica, na maioria das vezes, em significativas alterações na vida diária dos universitários já que a maioria passa a sair do convívio familiar e também acaba por enfraquecer ou extinguir os elos afetivos e sociais com os antigos amigos. Para as autoras, a academia pode promover a construção de uma nova rede de relações de apoio, com potencial para produzir o bem estar e a adaptação acadêmica de forma satisfatória.

Ao analisar a percepção dos estudantes sobre o apoio social recebido, constataram que a interação positiva e o apoio afetivo são melhores percebidos pelos universitários. Com relação à análise de apoio social e a variável gênero, as mulheres perceberam maior apoio social-afetivo/emocional/informação do que os homens. Ao analisar a correlação entre apoio social e autoconceito, as autoras apontam uma correlação positiva entre as variáveis tendo em vista que os estudantes que se declaram satisfeitos pessoalmente e com melhor autoestima passam a se perceber mais apoiados socialmente nos aspectos de informação, emocional e afetivo, além de estabelecerem interações sociais positivas. Quanto mais elevada a percepção de apoio social proveniente de grupos específicos como pai, mãe, família, amigos e grupos construídos no contexto acadêmico, como colegas e professores, mais positivas e satisfatórias são as percepções dos universitários sobre o período universitário.
Salientamos o estudo realizado pela fundação espanhola Atenea sobre a inclusão social da população dependente de drogas (Vicent, 2015), que ressalta a importância dos fatores macrossociais no processo de exclusão de usuários de drogas. Dentre os fatores macrossociais, a imagem social emergiu como elemento essencial nos processos de inclusão-exclusão. Tal imagem representa, na maioria dos casos, um consenso social negativo, constituído de preconceitos e estereótipos, que afeta significativamente a autoestima e autopercepção dessas pessoas e, consequentemente, afeta a inclusão destas na sociedade. Os autores, utilizando a teoria das representações sociais como aporte metodológico, enfatizam o fato de que a incorporação da perspectiva de gênero torna-se uma premissa importante quando se trata de identificar e analisar as representações sociais existentes sobre aqueles que fazem o uso de drogas. As mulheres, por exemplo, tem a imagem muito mais estigmatizada e rejeitada do que a dos homens na mesma situação e esse aumento do estigma, segundo os autores, está vinculado ao fato de que as mulheres, ao usarem drogas, rompem completamente com os papéis e tarefas que lhes são socialmente atribuídas como "se cuidar", "ser bonita" ou "se conectar emocionalmente com outras pessoas". O estudo conclui que o imaginário social sobre os usuários de drogas é atravessado principalmente por dois eixos da desigualdade: classe social e gênero. Outros eixos seriam a idade, etnia e local de origem. Uma imagem social constituída de preconceitos e estereótipos tem como consequência a criação de uma identidade carregada de aspectos negativos e culpabilidade. Como resultado, a pessoa que está nesse processo terá muita dificuldade em reconhecer os seus problemas e sentirá desamparo diante deles, terá a autoestima retirada e a incapacidade de se reconhecer em outros grupos e representações, ou seja, sofrerá rejeição social. Tais consequências são ainda mais graves e potencializadoras no caso de mulheres e pessoas de classe social desfavorecida.

Embora os resultados aqui apresentados tenham caráter exploratório, acreditamos que tais dados, como bem apontam Matias e Martinelli (2017), devem proporcionar a ampliação de discussões relacionadas à esfera acadêmica com vistas a promover auxílio às instituições de ensino superior e aos docentes para que estes possam identificar fatores relacionados ao desenvolvimento psicossocial dos universitários. Entendemos que a questão do uso do álcool e drogas relaciona-se com a desigualdade social e, destarte, está vinculada às condições e relações sociais e 
também às situações de vulnerabilidade. Dessa forma, para que um programa de prevenção se torne eficiente, este deve, portanto, pautar-se no conhecimento sobre as características e especificidades da população-alvo, assim como nas análises de padrões de consumo e dados sociodemográficos. Tais informações fornecerão os subsídios necessários para a definição do tipo de intervenção a ser implementada.

\section{Conclusão}

A análise dos padrões de consumo e comportamentos relacionados ao uso e abuso de drogas é essencial para a realização de ações eficazes de promoção da saúde sobre a população universitária, assim como os efeitos do meio social na saúde dos indivíduos, pois estes concebem os laços sociais como influentes nos comportamentos em relação à saúde e à doença, afetando as capacidades adaptativas em diversas situações.

Com base nos achados entende-se que cabe a instituição de ensino superior assegurar e favorecer o processo de socialização dos estudantes propiciando uma melhor adaptação e conscientização dos mesmos sobre o processo de transição ao mundo acadêmico, assim como as frustrações, insatisfações e diversos entraves que possam vir ocorrer ao longo deste processo. Buscando cumprir com as funções sociais e científicas é imprescindível que o ambiente acadêmico seja propício não só a aquisição de conhecimento, mas também ao processo de socialização, e para que isso ocorra a instituição deve prover formas de contato e aproximação com o contexto dos universitários, passando também pela melhoria nos espaços físicos das universidades destinados aos universitários, e a partir dessa interação criar intervenções de cunho preventivo com relação ao uso de substâncias psicoativas promovendo a redução das situações de risco ou vulnerabilidade dos indivíduos. Ao apontarmos padrões de consumo, frequências de comportamentos relacionados ao uso e abuso dessas substâncias e o uso nocivo, torna-se, de grande importância, concomitantemente o planejamento de ações e intervenções específicas. Embora de uma importância significativa, prover análises que envolvam o apoio social e as redes sociais é, portanto, apenas um dos aspectos a serem avaliados frente a imensa complexidade e importância dos aspectos envolvidos no consumo de substâncias psicoativas.
Tendo em vista as limitações dos instrumentos utilizados e o viés quantitativo deste estudo, torna-se necessário a ampliação de estudos cujas pretensões devam atender as especificidades dos universitários, sejam elas pessoais, interpessoais, ambientais ou familiares e, dessa forma, contextualizar os fatores de riscos e vulnerabilidades do estudante universitário, gênero, sociais, individuais e programáticas, ao consumo de bebidas alcoólicas e outras drogas.

Concordamos com Lima (2013) que ressalta a importância de implementar atividades reflexivas com o intuito de proporcionar a estimulação da capacidade crítica e autopercepção nas práticas de Educação em Saúde afim de que o público-alvo possa ampliar seus horizontes e projetos de vida. Essa proposta parte do pressuposto de que não se deve dar as mesmas respostas a todos os usuários de drogas, como, por exemplo, a abstinência. Deve-se, portanto, existir uma perspectiva mais ampla que possa promover mudanças, incluindo assim, a promoção de saúde, a educação dialógica e problematizado$\mathrm{ra}$, e as estratégias de redução de riscos e danos. A prevenção seria muito mais eficaz se fosse centrada no estímulo e corresponsabilização dos usuários quanto a sua relação com a droga, de modo que estes possam identificar e examinar os riscos e danos atrelados ao consumo.

Ao contrário da política atual, com ações fundamentadas no princípio da intolerância e desrespeito às escolhas individuais, as abordagens educativas em saúde podem proporcionar um posicionamento crítico e reflexão sobre a redução de danos de modo a elaborar ações estratégicas de proteção, cuidado e autocuidado. A proposta do apoio social pode ser de grande importância para os profissionais que lidam com a educação em saúde, e que estejam preocupados com o destino das populações vulneráveis.

\section{Contribuições dos autores}

Evangelista, V. M. A. participou da concepção, delineamento, coleta de dados da pesquisa, análise estatística dos dados da pesquisa, interpretação dos resultados e redação do artigo científico. Kadooka, A. participou da coleta de dados da pesquisa, análise estatística dos dados da pesquisa, e interpretação dos resultados. Pires, M. L. N. e Constantino, E. P. participaram da concepção, delineamento, análise estatística dos dados da pesquisa e interpretação dos resultados. 


\section{Conflitos de interesses}

Nenhum conflito financeiro, legal ou político envolvendo terceiros (governo, empresas e fundações privadas, etc.) foi declarado para nenhum aspecto do trabalho submetido (incluindo, mas não se limitando a subvenções e financiamentos, participação em conselho consultivo, desenho de estudo, preparação de manuscrito, análise estatística, etc.).

\section{Referências}

Alves, C. F., \& Dell'Aglio, D. D. (2015). Apoio Social e Comportamentos de Risco na Adolescência. Psico, 46(2), 165-175. Recuperado de https://revistaseletronicas.pucrs. br/ojs/index.php/revistapsico/article/view/18250. doi: 10.15448/1980-8623.2015.2.18250

Barceló, M. V., Socias, C. O., \& Brage, L. B. (2015). Efectos de los programas univesitarios en personas mayores en su red y apoyo social: el ejemplo de la universitat oberta per a majors. Revista Interuniversitária, (25), 301-320. Recuperado de https://recyt.fecyt.es/index.php/PSRI/ article/view/38033. doi: 10.7179/PSRI_2015.25.13

Bastos, F. I. P. M., Vasconcellos, M. T. L., De Boni, R. B., Reis, N. B., \& Coutinho, C. F. S. (2017). III Levantamento Nacional sobre o uso de drogas pela população brasileira. Rio de Janeiro: FIOCRUZ/ICICT. Recuperado de https://www.arca.fiocruz. $\mathrm{br} / \mathrm{handle} / \mathrm{icict} / 34614$

Brandão, B., \& Caracho, M. (2019). A nova política nacional sobre drogas e as comunidades terapêuticas. Le Monde Brasil Diplomatique, (145). Recuperado de https://diplomatique. org.br/a-nova-politica-nacional-sobre-drogas-e-ascomunidades-terapeuticas/

Brasil. Secretaria Nacional de Políticas sobre Drogas. (2010). I Levantamento Nacional sobre o Uso de Álcool, Tabaco e Outras Drogas entre Universitários das 27 Capitais Brasileiras. Brasília: Secretaria Nacional de Políticas sobre Drogas. Recuperado de https://cetadobserva.ufba.br/es/ publicacoes/i-levantamento-nacional-sobre-uso-de-alcooltabaco-e-outras-drogas-entre-universitarios

Cantos, R. (2015). Barreras a la inclusión social de población drogodependiente cronificada. Análisis desde la perspectiva de género. Madrid: Fundación Atenea.

Carlini, E. A. (Superv.) (2006). II Levantamento domiciliar sobre o uso de drogas psicotrópicas no Brasil : estudo envolvendo as 108 maiores cidades do país - 2005. São Paulo: Centro Brasileiro de Informação sobre Drogas Psicotrópicas, Universidade Federal de São Paulo. Recuperado de https://cetadobserva.ufba.br/sites/cetadobserva.ufba.br/ files/632.pdf
Chor, D., Griep, R. H., Lopes, C. S., \& Faerstein, E. (2001). Medidas de rede e apoio social no Estudo Pró-Saúde: pré-testes e estudo piloto. Cadernos de Saúde Pública, 17(4), 887-896. Recuperado de https://www.scielo.br/ scielo.php?pid=S0102-311X2001000400022\&script=sci abstract\&tIng=pt. doi: 10.1590/S0102-311X2001000400022

Eckschmidt, F., Andrade, A. G., \& Oliveira, L. G. (2013). Comparação do uso de drogas entre universitários brasileiros, norte-americanos e jovens da população geral brasileira. Jornal Brasileiro de Psiquiatria, 62(3), 199-207. Recuperado de https://www.scielo.br/scielo. php?pid=S0047-20852013000300004\&script=sci abstract\&tlng=pt. doi: 10.1590/S0047-20852013000300004

Elicker, E., Palazzo, L. S., Aerts, D. R. G. C., Alves, G. G., \& Câmara, S. (2015). Uso de álcool, tabaco e outras drogas por adolescentes escolares de Porto VelhoRO, Brasil. Epidemiologia e Serviços de Saúde, 24(3), 399-410. Recuperado de https://www.scielo.br/scielo. php?pid=S2237-96222015000300399\&script=sci_ abstract\&tIng=pt. doi: $10.5123 /$ S1679-49742015000300006

Galduróz, J. C. F., Nodo, A. R., Fonseca, A. M., \& Carlini, E. A. (2005). $\checkmark$ levantamento sobre o uso de drogas entre estudantes do Ensino Fundamental e Médio da Rede Pública de Ensino nas 27 Capitais Brasileiras-2004. Centro Brasileiro de Informações sobre Drogas Psicotrópicas-CEBRID: Departamento de Psicobiologia da Universidade Federal de São Paulo. Recuperado de https://bit.ly/3318zTj

Graner, K. M., \& Cerqueira, A. T. A. R. (2019). Revisão integrativa: sofrimento psíquico em estudantes universitários e fatores associados. Ciência \& Saúde Coletiva, 24(4), 1327-1346. Recuperado de https://www. scielo.br/scielo.php?script=sci_abstract\&pid=S1413$81232019000401327 \&$ Ing=en\&nrm=iso\&tlng=pt. doi: 10.1590/1413-81232018244.09692017

Griep, R. H., Chor, D., Faerstein, E., Werneck, G. L., \& Lopes, C. S. (2005). Validade de constructo de escala de apoio social do Medical Outcomes Study adaptada para o português no Estudo Pró-Saúde. Cadernos de Saúde Pública, 21(3), 703-714. Recuperado de https://www.scielo.br/scielo. php?script=sci_arttext\&pid=S0102-311X2005000300004\&l ng=pt\&nrm=iso. doi: $10.1590 / 50102-311 \times 2005000300004$

Henrique, I. F. S., Micheli, D., Lacerda, R. B., Lacerda, L. A., \& Formigoni, M. L.O. S. (2004). Validação da versão brasileira do teste de triagem do envolvimento com álcool, cigarro e outras substâncias (ASSIST). Revista da Associação Médica Brasileira , 50(2), 199-206. Recuperado de https://www.scielo.br/scielo.php?script=sci_ arttext\&pid=S0104-42302004000200039. doi: $10.1590 /$ s0104-42302004000200039 
Lima, E. H. (2013). Educação em Saúde e Uso de Drogas: Um Estudo Acerca da Representação das Drogas para Jovens em Cumprimento de Medidas Educativas (Tese de Doutorado). Fundação Oswaldo Cruz. Belo Horizonte, BH, Brasil. Recuperado de https://www.arca.fiocruz.br/handle/ icict/7244

Lima, L. M. R., Gomide, S. J., \& Farinha, M. G. (2015). Uso de drogas por universitários de cursos exclusivamente noturnos. Revista do NUFEN, 7(2), 99-136. Recuperado de http://pepsic.bvsalud.org/scielo.php?script=sci_ arttext\&pid=S2175-25912015000200006

Matias, R. C., \& Martinelli, S. C. (2017). Um estudo correlacional entre apoio social e autoconceito de estudantes universitários. Revista da Avaliação da Educação Superior, 22(1), 15-33. Recuperado de https://www. scielo.br/scielo.php?script=sci_arttext\&pid=S141440772017000100015\&lng=en\&nrm=iso. doi: $\underline{10.1590 /}$ s1414-40772017000100002

Sanchez, Z. V. D. M., \& Nappo, S. A. (2007). A religiosidade, a espiritualidade e o consumo de drogas. Archives of Clinical Psychiatry, 34(suppl.1), 73-81. Recuperado de https://www.scielo.br/scielo.php?script=sci_ arttext\&pid=S0101-60832007000700010. doi: $10.1590 /$ S0101-60832007000700010

Santos, E. O., \& Campagnac, V. (2018). A construção de políticas públicas sobre drogas ilícitas no Brasil: entre a repressão e a prevenção. Cadernos de Segurança Pública, 10(10). Recuperado de http://www.isprevista.rj.gov.br/download/ Rev20181003.pdf

Sherbourne, C. D., \& Stewart, A. L. (1991). The MOS social support survey. Social Science \& Medicine, 32(6), 705-714. Recuperado de https://www.sciencedirect.com/science/ article/abs/pii/027795369190150B. doi: 10.1016/02779536(91)90150-B

Siqueira, L. D’E., Bastos, M. F. G., Santos, A. N., \& Silva, M. P. M. (2017). Profile of students admitted to health service at university. Revista Brasileira em Promoção da Saúde, 30(3), 1-8. Recuperado de https://search. proquest.com/openview/9ebe565bb69f6df6864500d b25eff329/1?pq-origsite=gscholar\&cbl=2046042. doi: 10.5020/18061230.2017.6218

Souza, J. (2010). Percepção de apoio social e caracterização da rede de dependentes e não dependentes de substâncias psicoativas (Tese de Doutorado). Universidade de São Paulo, Ribeirão Preto, SP, Brasil. Recuperado de https:// cetadobserva.ufba.br/sites/cetadobserva.ufba.br/ files/403.pdf
Squassoni, C. E., Matsukura, T. S., \& Panúncio-Pinto, M. P. (2016). Versão brasileira do Social Support Appraisals: estudos de confiabilidade e validade. Revista de Terapia Ocupacional da Universidade de São Paulo, 27(1), 1-11. Recuperado de http://www.revistas.usp.br/rto/article/view/107285. doi: 10.11606/issn.2238-6149.v27i1p1-11

Targino, R., \& Hayasida, N. (2018). Risco e proteção no uso de drogas: revisão da literatura. Psicologia, Saúde \& Doenças, 19(3), 724-742. Recuperado de http://www.scielo.mec.pt/scielo.php?script=sci_ arttext\&pid=S1645-00862018000300020. doi: 10.15309/18psd190320

United Nations Office on Drugs and Crime. (2018). World Drug Report 2018. Pre-briefing to the Member States [Internet]. Recuperado de https://www.unodc.org/wdr2018/ prelaunch/Pre-briefingAM-fixed.pdf 